\title{
Effects of Relative Humidity and Temperature on the Transport of Chloride in the Concrete
}

\author{
Jin-Gak Nam ${ }^{1)}$, William H. Hartt ${ }^{1)}$, and Ki-Joon $\mathrm{Kim}^{2)^{*}}$ \\ 1) Florida Atlantic University, Florida, USA \\ ${ }^{2)}$ Korea Maritime University Busan, 606-791, Korea
}

(Received November 10, 2004, Accepted May 16, 2005)

\begin{abstract}
To investigate the role of $\mathrm{RH}$ and temperature on the transport of chloride in the concrete, two groups of specimens were configured. For both groups, mix design was based on $\mathrm{w} / \mathrm{c}=0.45 ; 400 \mathrm{~kg} / \mathrm{m}^{3}$ cement, $794 \mathrm{~kg} / \mathrm{m}^{3}$ fine aggregate and $858 \mathrm{~kg} / \mathrm{m}^{3}$ coarse aggregate. After specimen fabrication these were exposed to four different $\mathrm{RH}(35,55,75$ and $95 \% \mathrm{RH})$ and temperature $\left(0,20,30\right.$ and $\left.40^{\circ} \mathrm{C}\right)$ conditions. After 3 and 6 months $15 \% \mathrm{NaCl}$ exposure $5 \mathrm{~mm}$ cores were taken. These cores were sliced and individual cores were ground to powder. In addition, to evaluate the effect of temperature on the chloride binding some powder samples were leached in the each of four temperature chambers. Chloride titration for these was performed using FDOT acid titration method. Based upon the resultant data conclusions were reached regarding that 1) effective diffusion coefficient, $\mathrm{D}_{\mathrm{e}}$, increased with increasing exposure $\mathrm{RH}$, suggesting that the size and number of water paths increased with elevated moisture content in the specimens, 2) $D_{e}$ increased with increasing temperature in the range of 0 to $40^{\circ} \mathrm{C}$ possibly by elevated thermal activation of chloride ions and reduced chloride binding at higher temperature, 3 ) water soluble chloride concentration, $\left[\mathrm{Cl}^{-}\right]_{\mathrm{s}}$, increased with increasing temperature, and 4) chloride concentration profile for initially dry concrete specimens was higher than for the initially wet ones indicating pronounced capillary suction (sorption) occurred for the dry concrete specimens.
\end{abstract}

Keywords: relative humidity, temperature, chloride, diffusion, chloride binding

\section{Introduction}

Chloride transport in concrete has been received much attention due to the problem of chloride-induced corrosion of reinforcement in concrete structures built at coastal area. The mechanism of $\mathrm{Cl}^{-}$intrusion into concrete invariably involves both capillary suction (sorption) and diffusion; however, for situations where the depth to which sorption occurs is relatively shallow compared to the reinforcement cover, only diffusion alone is considered as the $\mathrm{Cl}^{-}$transport process. ${ }^{1,2)}$ That is, transport of $\mathrm{Cl}^{-}$inside of concrete is commonly assumed to be governed solely by Fick's laws. The following equation (1) shows the solution of Fick's second law for a one-dimensional system;

* Corresponding author

Email address: corr@hhu.ac.kr

(C2005 by Korea Concrete Institute

$$
C(x, t)=C s\left\{1-\operatorname{erf}\left[\frac{x}{2 \sqrt{D_{e} t}}\right]\right\}
$$

where, $\mathrm{C}(\mathrm{x}, \mathrm{t})$ is the chloride concentration at depth $\mathrm{x}$ after time $t, \mathrm{C}_{\mathrm{s}}$ is the $\left[\mathrm{Cl}^{-}\right]$at the exposed surface, and $\mathrm{D}_{\mathrm{e}}$ is the effective diffusion coefficient. Assumptions involved in arriving at this solution are, first, the initial [Cl] in the concrete is negligible, second, $C_{s}$ and $D_{e}$ are constant with time and, third, the diffusion is "Fickian"; that is, there are no $\mathrm{Cl}^{-}$ sources or sinks in the system.

However, for atmospherically exposed concrete, $C_{s}$ is likely to increase with time, although steady-state values generally in the range $0.3 \sim 0.7$ (percent of concrete weight) have been six months. ${ }^{3)}$ Factors that effect include type of exposure, mix design, and curing conditions. ${ }^{4)}$ The diffusion coefficient that is calculated from Equation (1) is an "effective" value since it is weighted over the relevant ex- 
posure period due, first, to the fact that $\mathrm{C}_{\mathrm{s}}$ may vary, second, because of progressive cement hydration with time, and, lastly, chemical and physical $\mathrm{Cl}^{-}$binding. That is, the chloride diffusion may vary with concrete age, ${ }^{5,6)}$ exposure conditions ${ }^{7,8)}$ and $\mathrm{Cl}^{-}$binding. ${ }^{9)}$

Further complications arise from the different aspect of chloride diffusion and its binding between the surface layer and the bulk of concrete. ${ }^{10-12)}$ The surface layer of concrete is more porous than bulk of inside concrete due to excess water bleeding at the surface region and relatively dry compared to that of inside concrete. ${ }^{13)}$ Therefore, chloride ions move into concrete mainly in two consecutive mechanisms. First, chloride ions move into concrete through the moving water (sorption), and, second, diffused by concentration gradient in non-moving water (diffusion). At the early exposure, that is, relative fast water uptake occurs at the dried shallow depth by typical capillary suction, however, the rate decrease with time ${ }^{14)}$; chloride movement through moving water becomes negligible with time and finally only diffusion by concentration gradient becomes dominant. Thus, most of the models currently available assume that chloride transport is dictated by diffusion alone. However, such an approach using Fick's second law for a one-dimensional system may not be valid for conditions which involve significant initial sorption, time dependent surface concentration, and chloride binding by cement hydration.

When fresh concrete is exposed to the ambient air, the moisture distribution of inside concrete becomes nonuniform as a result of its diffusion and self-desication. ${ }^{15)}$ As moisture content decrease in the concrete, the size and number of water paths decrease, therefore, diffusion of chloride ions decreases. ${ }^{16)}$ Also, temperature has a major influence on the diffusion coefficient; temperature elevation increase diffusion rate by elevating thermal activation of diffusion process and reduce the binding capacity. ${ }^{17,18 i}$ Even though the degree of relative humidity of exposure condition is crucial parameter for the moisture distribution of inside concrete, very little work has been done to quantify the its effect on the chloride diffusion. Also, few dita are available to show the effects of temperature on chlloride diffusion and binding. Thus, the objective of this research is to provide better understanding of the role of relative humidity and temperature on the transport process of clyloride ions in the concrete and evolution of diffusion coefficient with time at early exposure period.

\section{Experimental procedures}

\subsection{Specimen configuration and exposure}

To investigate the role of $\mathrm{RH}$ and temperature on $\mathrm{D}_{\mathrm{e}}$, two groups of specimens were configured. Table 1 describes these and lists the exposure conditions. For both specimen groups, mix design was based on $\mathrm{w} / \mathrm{c}=0.45,400 \mathrm{~kg} / \mathrm{m}^{3}$ cement, $794 \mathrm{~kg} / \mathrm{m}^{3}$ fine aggregate, and $858 \mathrm{~kg} / \mathrm{m}^{3}$ coarse aggregate. And, Table 2 shows the compositional analysis of used cement. For group 1 ( $\mathrm{RH}$ exposure), four identical sets of specimens were prepared. Each set has two identical specimens for chloride exposure and one for RH measurement inside the concrete.

Fig. 1 schematically describes the dimensions of the two types of cylindrical specimens. As listed in Table 1, sets of specimens were exposed to four different RH conditions (target RH 35, 55, 75, and 95\%). Fig. 2 schematically illustrates the RH exposure chambers for group 1. Conditions of RH 35 and 55\% were achieved using the appropriate mix of $\mathrm{RH} \sim 20 \%$ and $\mathrm{RH}$ $\sim 75 \%$ air. The RH 75 and $95 \%$ conditions were achieved by the placement of saturated $\mathrm{NaCl}$ and tap water in the chamber

Table 1 List of the specimen configuration

\begin{tabular}{|c|c|c|c|c|c|c|c|c|}
\hline \multicolumn{4}{|c|}{ Group 1 : Relative humidity } & \multicolumn{5}{|c|}{ Group 2: Temperature } \\
\hline $\begin{array}{l}\text { Specimen } \\
\text { ID }\end{array}$ & $\begin{array}{c}\text { Exposure } \\
\text { RH (\%) }\end{array}$ & $\begin{array}{l}\text { Chloride } \\
\text { analysis }\end{array}$ & $\begin{array}{l}\text { Chloride } \\
\text { exposure }\end{array}$ & Specimen ID & $\begin{array}{c}\text { Exposure } \\
\mathrm{T}\left({ }^{\circ} \mathrm{C}\right)\end{array}$ & $\begin{array}{l}\text { Concrete } \\
\text { condition }\end{array}$ & $\begin{array}{l}\text { Chloride } \\
\text { analysis }\end{array}$ & $\begin{array}{l}\text { Chloride } \\
\text { exposure }\end{array}$ \\
\hline RH35-6M & 35 & \multirow{5}{*}{$\begin{array}{c}\text { At } 6 \\
\text { months }\end{array}$} & \multirow{5}{*}{$\begin{array}{l}\text { Spray at every } \\
\text { other day } \\
\text { using } 15 \% \\
\mathrm{NaCl} \text { solution }\end{array}$} & T0W-3M & 0 & Wet & \multirow{5}{*}{$\begin{array}{c}\text { At } 3 \\
\text { months }\end{array}$} & \multirow{5}{*}{$\begin{array}{l}\text { Continuous } \\
\text { ponding } \\
\text { using } \\
15 \% \mathrm{NaCl} \\
\text { solution }\end{array}$} \\
\hline RH55-6M & 55 & & & $\mathrm{~T} 20 \mathrm{~W}-3 \mathrm{M}$ & 20 & Wet & & \\
\hline RH75-6M & 75 & & & T30W-3M & 30 & Wet & & \\
\hline RH95-6M & 95 & & & T40W-3M & 40 & Wet & & \\
\hline RHS-6M & $35 \sim 95$ & & & TSW-3M & $20 \sim 40$ & Wet & & \\
\hline
\end{tabular}

Table 2 Compositions of cement.

\begin{tabular}{l|l|l|l|l|l|l|l|l}
\hline Compound & $\mathrm{SiO}_{2}$ & $\mathrm{Al}_{2} \mathrm{O}_{3}$ & $\mathrm{Fe}_{2} \mathrm{O}_{3}$ & $\mathrm{CaO}_{2}$ & $\mathrm{MgO}$ & $\mathrm{SO}_{3}$ & $\mathrm{Na}_{2} \mathrm{O}$ & $\mathrm{K}_{2} \mathrm{O}$ \\
\hline \hline $\mathrm{Wt} \%$ & 21.88 & 5.64 & 3.87 & 64.42 & 0.98 & 2.87 & 0.164 & 0.54 \\
\hline
\end{tabular}




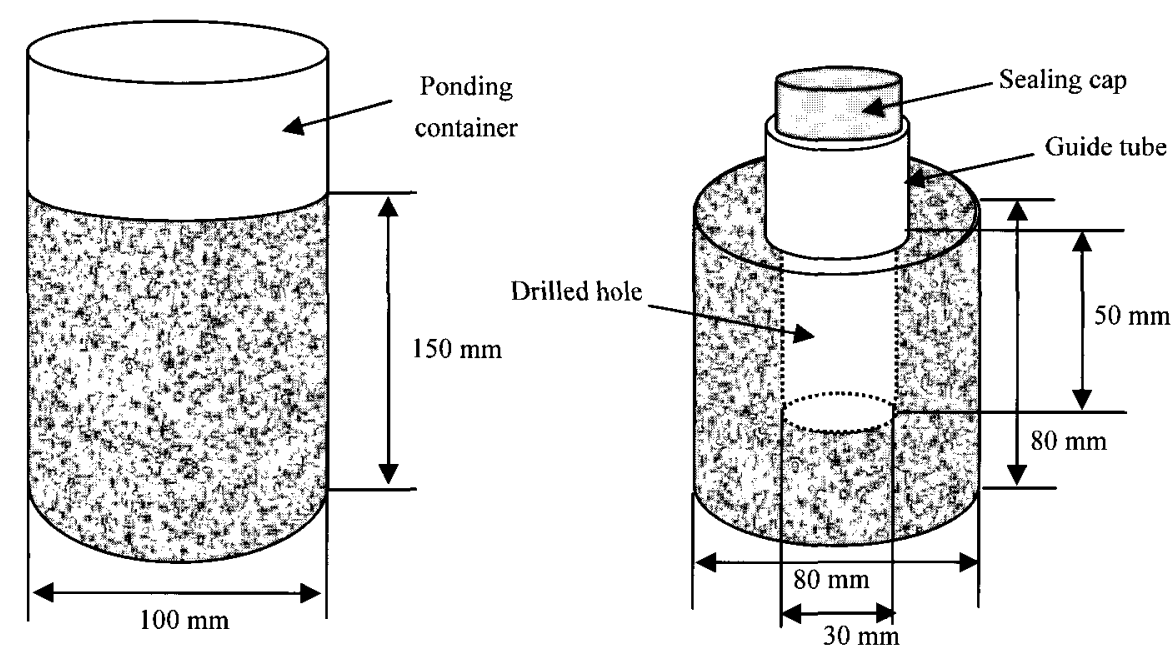

(a) Specimen for chloride exposure

(b) Specimen for RH measurement

Fig. 1 Schematic illustration of the dimension of two types of cylindrical specimens

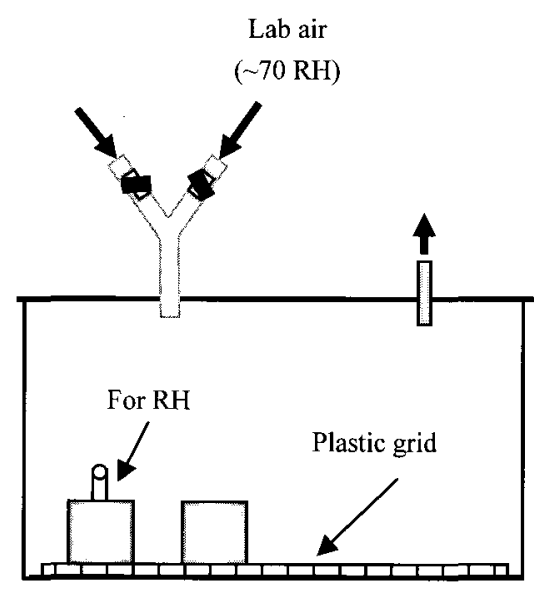

(a) 35 and $55 \%$ RH Chambers

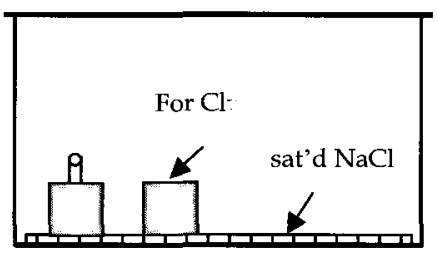

(b) $75 \%$ RH Chambers

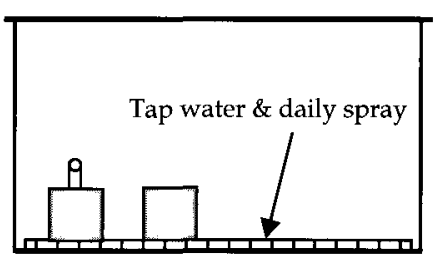

(c) $95 \% \mathrm{RH}$ Chambers

Fig. 2 Schematic diagrams of RH exposure chambers

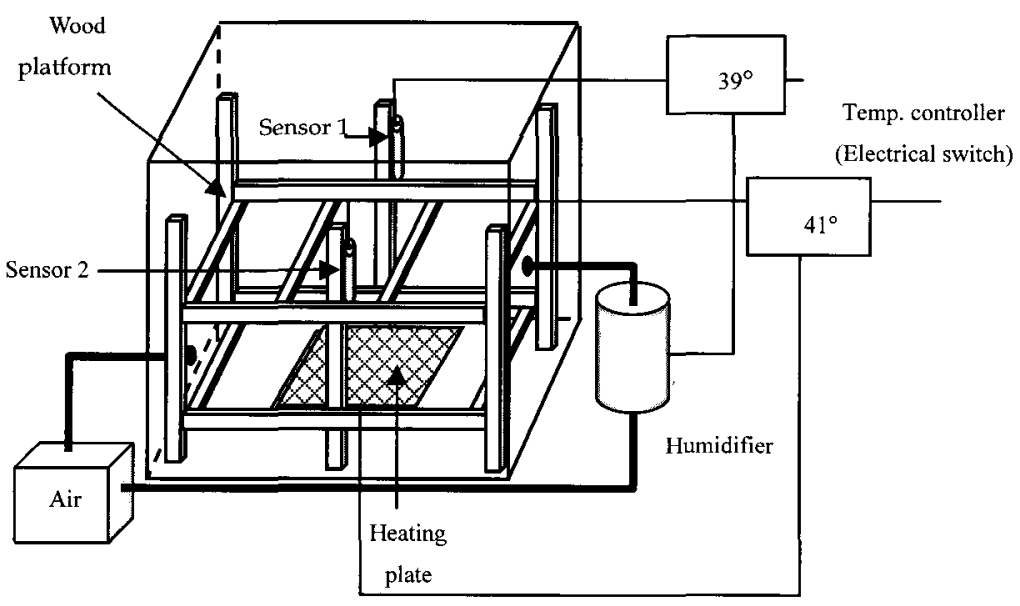

Fig. 3 Schematic illustration of the controlled temperature chamber 
bottom, respectively. Chloride exposures for these types of specimens were performed every other day by spraying using $15 \% \mathrm{NaCl}$ solution to accelerate corrosion process. For group 2 (temperature exposure), specimens were fabricated with dimensions the same as in Fig. 1 (a). Four sets of two identical specimens were prepared. One set of specimens was exposed to each of four temperatures $\left(0^{\circ} \mathrm{C}\right.$ refrigerator, $20-23^{\circ} \mathrm{C}$ ambient laboratory air and 30 and $40^{\circ} \mathrm{C}$ constant temperature chambers). To achieve the 30 and $40^{\circ} \mathrm{C}$ constant temperature conditions, special chambers were fabricated based upon the wet and dry bulb principal. Aluminum shielded heating plate and air circulating pump were mounted in the chambers to provide uniformly high temperature. Fig. 3 illus trates the configuration of this type of chamber. These specimens for temperature exposure were continuously ponded with $15 \% \mathrm{NaCl}$ solution.

\subsection{Chloride analysis}

RH of the exposure chambers for group 1 and temperature for group 2 were monitored. RH inside the concrete was measured using a Fisher Scientific digital RH meter (Fig. 1 (b). After three and six month's exposure, the specimens listed in Table 1 were sliced and the individual slices ground to powder. In addition, four identical specimens of the same mix design and dimensions as the above two groups were ponded with salt water; and powder sampling and chloride analyses were performed after 1 and 10 days exposure. To evaluate the effect of concrete surface moisture condition on diffusion of chloride in concrete, two specimens (designated as D) were exposed to laboratory air $(\sim 60 \% \mathrm{RH})$ and two others (designated as $\mathrm{W})$ were ponded with tap water for one month before $15 \%$ $\mathrm{NaCl}$ ponding.

To understand the effect of temperature on chloride binding and chloride diffusion, water soluble chloride was measured using the modified AASHTO method designated T 26094. ${ }^{19)}$ For this crushed concrete particles which passed a $0.500 \mathrm{~mm}$ (No. 35) sieve and were retained on a $0.355 \mathrm{~mm}$ (No. 45) sieve were leached at $0,20,30$ and $40^{\circ} \mathrm{C}$ temperatures. In initial experiments, leaching took place for 1,2,3,5 and 10 days to evaluate the effect of leaching time. Also, to evaluate the effect of water-to-concrete powder ratio $(\varepsilon)$. four different water-powder ratios $(\varepsilon=0.5,1.0,2.0$ and 4.0) were assessed. The weight of the concrete particle samples for the individual determinations was $3 \mathrm{~g}$. Subsequently, a five day leaching period with $\varepsilon=1$ was employed. At the end of the leaching periods, samples were filtered using Whatman No. 41 paper and titrated using FDOT acid titration method. ${ }^{20)}$ Values for effective chloride diffusion coefficient, $D_{\mathrm{e}}$, were then calculated from the chloride concen- tration profile data using a least squares curve fitting, algorithm of equation (1). In cases where sorption was judged to be significant, only the part of the chloride profile which was judged to be "Fickian" was adapted to the curve-fitting.

\section{Results and discussion}

\subsection{Effects of RH on the transport of chloride}

RH monitoring results for the exposure chambers are shown in Fig. 4 which indicates that the data are generally scattered about the target RH levels. As shown in Fig. 1 (b), the cover for $\mathrm{RH}$ measurement specimens was $3 \mathrm{~cm}$. This relatively shallow cover probably enabled the $\mathrm{RH}$ here to generally track to the chamber value. However, it must be considered that $\mathrm{RH}$ at greater depths maintained relatively high values with little effects of external RH change. ${ }^{21)}$

Thus, the RH data described below probably represent variations for shallow cover depth. Fig. 5 shows the measured RH values indicated by the concrete embedded probe for specimen in the four different chambers. After 120 days, when

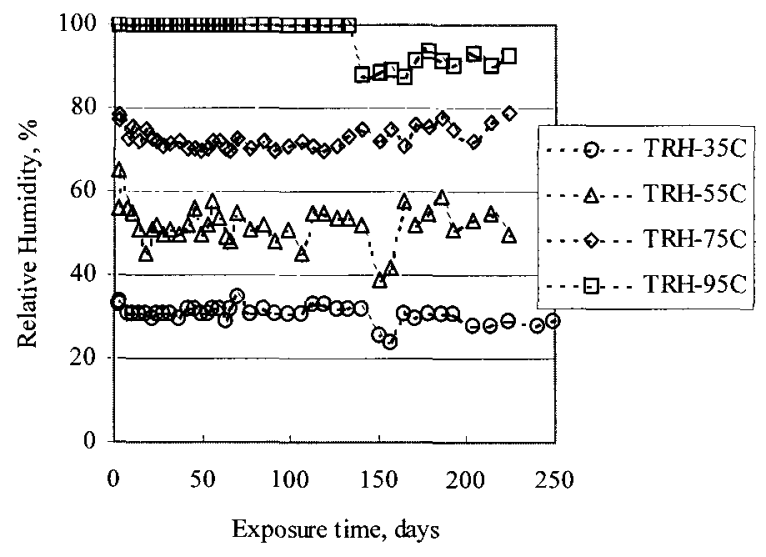

Fig. 4 data for chambers with target RH 35, 55, 75 and $95 \%$

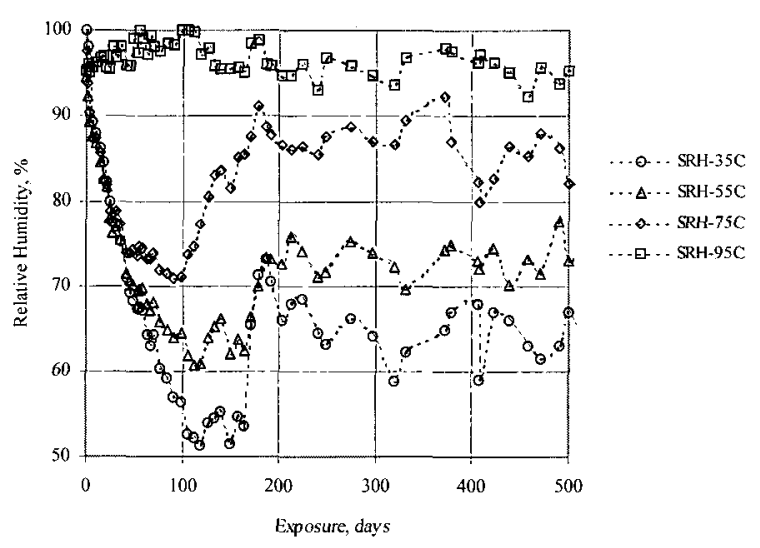

Fig. 5 Internal RH of concrete specimens exposed to $\mathrm{RH} 35,55,75$ and $95 \%$ chambers 
the internal $\mathrm{RH}$ became stable, a $15 \% \mathrm{NaCl}$ solution begun to spray on the top surface every other day. $\mathrm{RH}$ of inside the concrete began to increase thereafter; however, these changes remained ordered according to chamber RH level. Fig. 6 shows the chloride profiles for the first set of concrete specimens exposed to RH 35, 55,75 and $95 \%$ after about six months of salt spraying. This indicates that the chloride profile for $\mathrm{RH} 95 \%$ had the least concentration compared to the others. Surface of specimens exposed to the lower RH chambers became relatively dry compared to the RH 95\% one, facilitating chloride movement into the concretes by water suction. In the case of RH 35 and 55\% exposures the chloride concentration profiles dropped relatively sharply beyond the sorption zone (about $3 \mathrm{~cm}$ ). Chloride concentration for the $\mathrm{RH}$ $75 \%$ specimen was highest at depth indicating a combined effect of sorption and diffusion. Fig. 7 shows the chloride profile results for the second set of specimens which were exposed in normal laboratory air ( $\mathrm{RH} \sim 75 \%$ ) for about one month before being placed in the RH chambers, at which time salt spraying commenced. Thus, RH of the concrete surface was similar in each case at the beginning of spraying. This difference in initial exposure condition changed the chloride profile of the $\mathrm{RH} 95 \%$ speci-

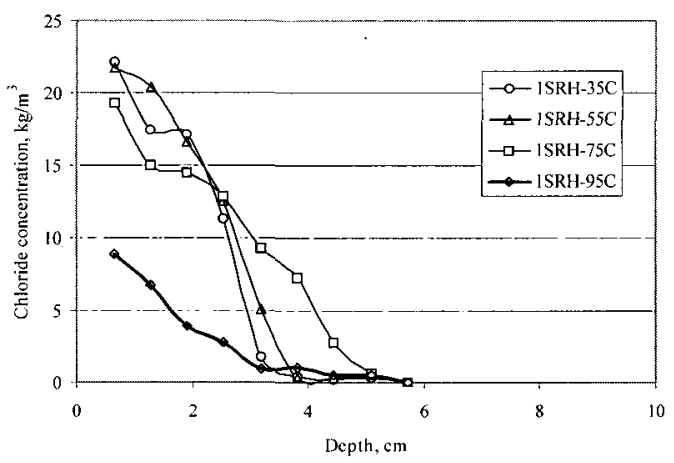

Fig. 6 Chloride profiles of set 1 concrete specmens exposed to RH 35, 55, 75 and $95 \%$ chambers after six months salt spray

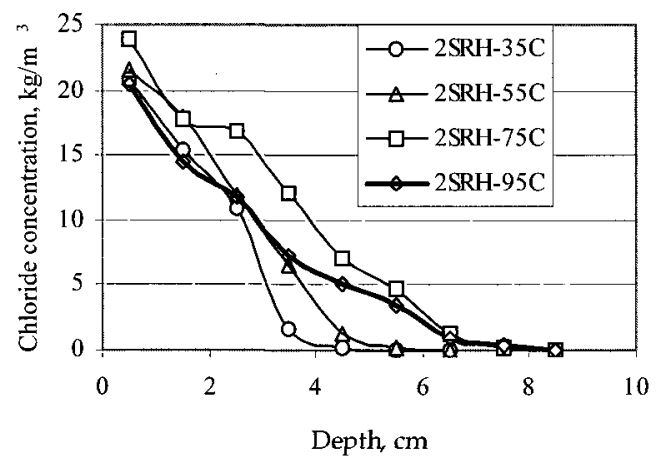

Fig. 7 Chloride distribution profile of concrete specimens exposed to $\mathrm{RH} 35,55,75$ and $95 \%$ chambers for 6 months men compared to the condition in set 1 . The great chloride concentration at shallow depth (set 2) suggests sorption played a great role here. Fig. 8 presents a plot of effective chloride diffusion coefficient, $\mathrm{D}_{\mathrm{e}}$ versus exposure $\mathrm{RH}$. As noted previously, where sorption is thought to have been significant only the part of chloride profile which was "Fickian" was adapted to the curve-fitting. The resultant data indicate that $D_{e}$ increased with increasing $R H$ for both specimen sets, suggesting that the size and number of water paths increased with elevated moisture content in the specimens.

\subsection{Effects of temperature on transport of chlorides in concrete}

The results of temperature monitoring for the exposure chambers are displayed in Figs. 9 11 show the chloride profile and diffusion coefficient plots, respectively, that resulted from these exposures. The latter data indicate that the chloride diffusion coefficient increased approximately exponentially with temperature. The reason for this is that increasing temperature increased diffusion rate by elevating thermal activation of chloride ions. An additional effect was reduced chloride binding with increasing temperature, as discussed subsequently. In addition, these data were analyzed using Arrhenius equation and the resultant plot showed that $\log \mathrm{D}_{\mathrm{e}}$ values were almost linear (R-squared was 0.904 and activation energy was $14.91 \mathrm{KJ} / \mathrm{mol}$ ) in the designated temperature range $\left(0 \sim 40^{\circ} \mathrm{C}\right)$ indicating that probably one transport mechanism was involved in chloride diffusion process in this temperature range.

Additional experiments were also performed to better understand the effect of temperature on chloride binding and diffusion. Initially, several tests were performed to qualify the modified AASHTO water soluble chloride measuring procedures. Fig. 12 shows the total chloride concentration of random samples from the same concrete

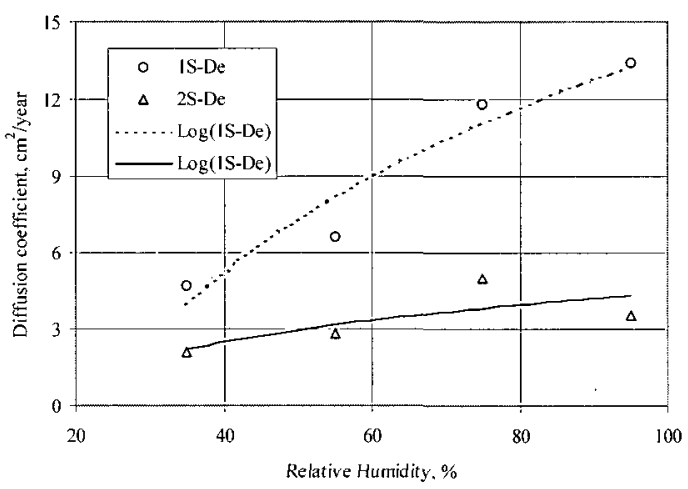

Fig. 8 Chloride diffusion coefficient as a function of exposure RH for first and second set specimens 


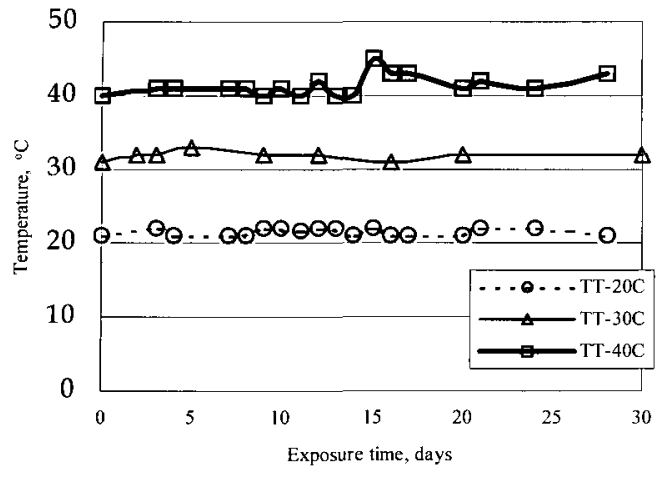

Fig. 9 Temperature data for the exposure chambers

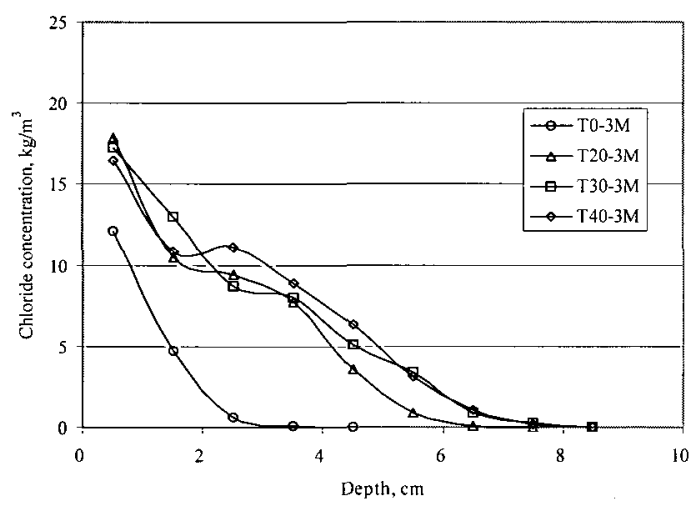

Fig. 10 Chloride concentration profiles for the different exposure temperatures

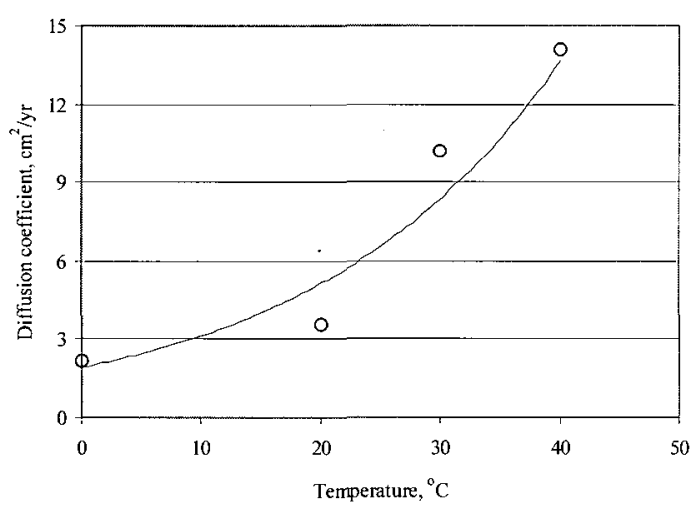

Fig. 11 Effective diffusion coefficient, $D_{e}$, as a function of exposure temperature

powder, indicating good reproducibility of samplings. Also, Figs. 13, 14 indicate that water versus particle ratio $(\varepsilon)$ and leaching period had little or no effect on the water solubility of chlorides within the range that investigated. A five day leaching period with water-to-powder ratio, $\varepsilon$, of one was employed for samples leached at four temperatures. In actual concrete pore structure, the water-to-particle ratio $(\varepsilon)$ can be extremely small; and the ratio may affect solubility.

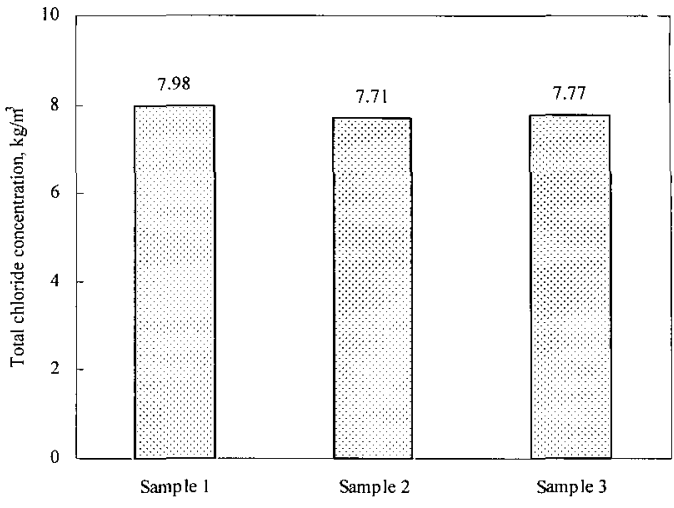

Fig. 12 Chloride concentration of random sample of concrete powder

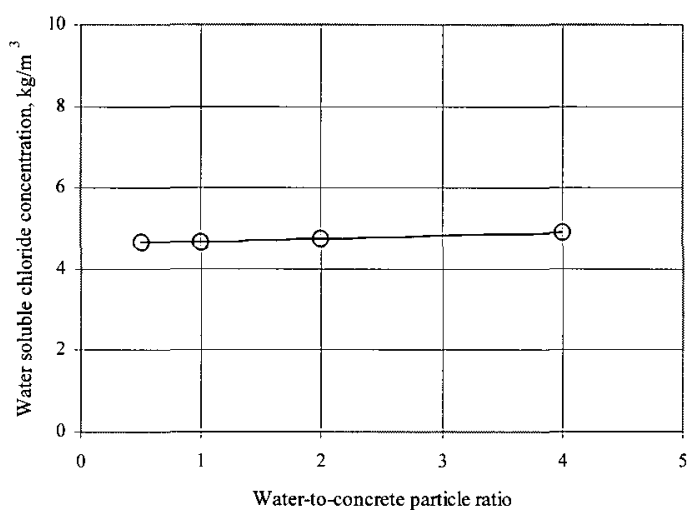

Fig. 13 The effect of water to particle ratio on chloride solubility

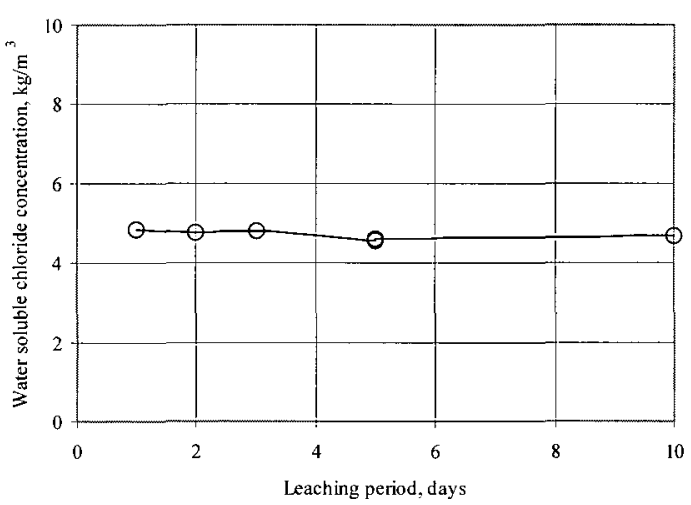

Fig. 14 The effect of leaching period on chloride solubility

Fig. 15 shows the effect of temperature on the concentration of chlorides leached from duplicate concrete powder samples. The general trend is one where water soluble chloride concentration, $\left[\mathrm{Cl}^{-}\right]_{\mathrm{s}}$, increased with increasing temperature, suggesting reduced chloride binding with increasing temperature. This reduced binding capacity at elevated temperature results in a higher concentration of free chlorides and, consequently, an increased flux of chlorides. 


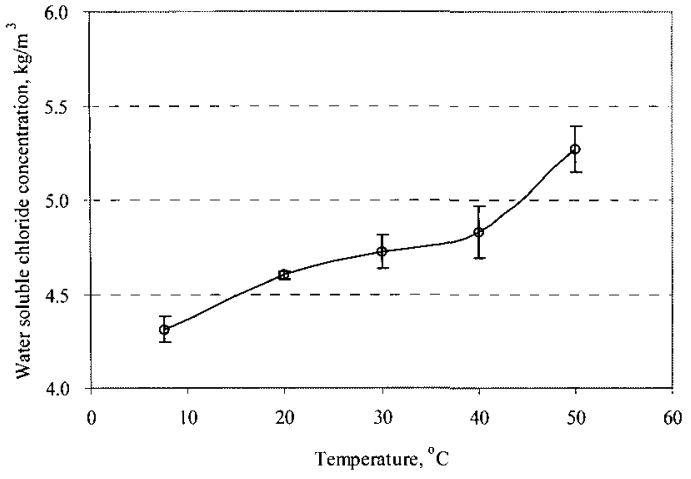

Fig. 15 Plot of average water soluble chloride concentration for duplicated concrete powder samples as a function of leaching temperature

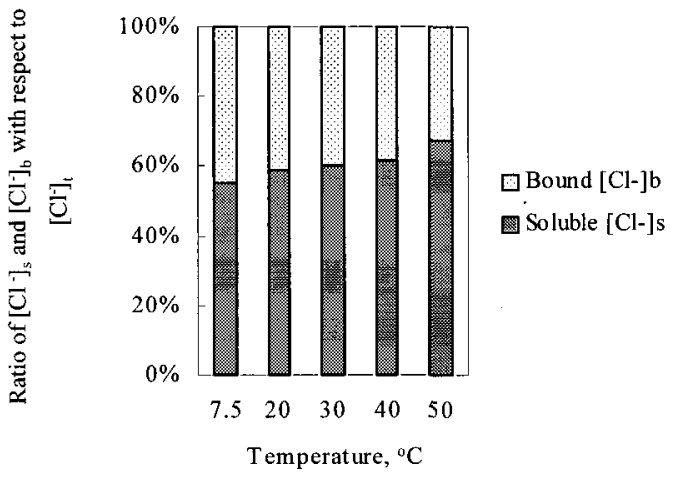

Fig. 16 Proportion of soluble and bound chloride

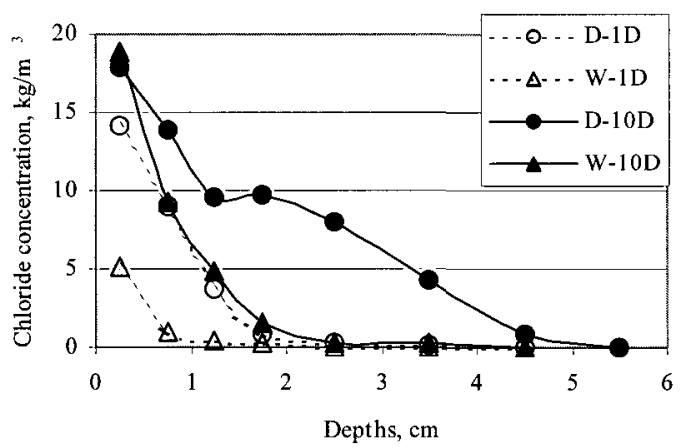

Fig. 17 Chloride profiles at 1 and 10 days $15 \% \mathrm{NaCl}$ ponding for specimens initially in dry or wet condition

According to Larsen, ${ }^{17)}$ the reason for the variation of balance between free and bound chloride in concrete is that temperature affects the equilibrium state between these two forms. Also, Fig. 16 describes the percentage of water soluble and bound chloride as a function of leaching temperature. This result indicates that about $60 \%$ of total chloride can be dissolved into the pore solution.

\subsection{Effects of concrete surface moisture condition}

Fig. 17 shows the effect of initial concrete surface moisture condition on the transport of chloride ions in concrete. The concentration profiles for the dried (D) concrete specimens were higher than for the initially wet (W) ones for both 1 and 10 days exposure. The difference probably resulted from capillary suction (sorption) during early exposure for the relatively dry concrete surfaces of the D-1D and D-10D specimens. Sorption was less significant for W1 and $\mathrm{W}-10 \mathrm{D}$ specimens because the surface was moisturized when $\mathrm{Cl}^{-}$exposure began. According to the chloride profile sorption for D-10D was not only limited to a shallow depth; but this also affected further chloride diffusion below sorption region by increasing chloride concentration level at about $2 \mathrm{~cm}$ depth. Also, remarkably increased surface chloride concentration was found at W-type compared with that of D-type one at 10 days, indicating further chloride diffusion for W-type can be accelerated by this increased surface concentration. This result was consistent with the result of $\mathrm{RH}$ exposure; in case of $\mathrm{RH} 95 \%$ the one showed the higher initial $\mathrm{RH}$ of inside of concrete revealed quite less chloride concentration profile and $D_{e}$ value.

\section{Conclusion}

The following conclusions were reached based upon exposure of a series of cylindrical specimens to a $15 \mathrm{w} / \mathrm{o} \mathrm{NaCl}$ solution.

1) The effective diffusion coefficient, $D_{e}$, increased with increasing exposure $\mathrm{RH}$, suggesting that the size and number of water paths increased with elevated moisture content in the specimens.

2) Chloride diffusion coefficient, $D_{e}$, increased approximately exponentially with increasing temperature in the range of 0 to $40^{\circ} \mathrm{C}$. The reason for this is that increasing temperature increased diffusion rate possibly by elevating thermal activation of chloride ions and reduced chloride binding at higher.

3) Water soluble chloride concentration, $\left[\mathrm{Cl}^{-}\right]_{s}$, increased with increasing temperature, suggesting reduced chloride binding as temperature increased. This reduced binding capacity at elevated temperature resulted in a higher concentration of free chlorides and, consequently an increased flux of chlorides into concrete.

4) Chloride concentration for initially dry concrete specimens was higher than for the initially wet ones. The difference between these two conditions resulted in more pronounced capillary suction (sorption) during early exposure for the initially dry concrete specimens. 


\section{References}

1. L. Tang, "Concentration Dependence of Diffusion and Migration of Chloride Ions Part 1.Theoretical Considerations," $\mathrm{Ce}$ ment and concrete research, Vol. 29, 1999, pp. 1463 1468.

2. J. Nam, W. Hartt, K.Kim, and L. Li, "Effect of Cement Alkalinity upon Time-to-Corrosion of Reinforcing Steel in Concrete Undergoing Chloride Exposure," paper no.03299, CORROSION/2003.

3. P. B. Bamforth, Definition of Exposure Classes and Concrete Mix Requirements for Chloride Contaminated Environments, Corrosion of Reinforcement in Concrete, Eds: Page, C.L., Treadaway, K.W.J., and P. B. Bamforth, Soc. Chem. Ind., London, 1996, pp. 176.

4. P. B. Bamforth and W. F. Price, Factors Influencing Chloride Ingress into Marine Structures, Concrete 2000, Eds: R. K. Dhir and M. R. Jones, E\&FN Spon, London, 1993, pp. 1105.

5. E. C. Bentz, C. M. Evans and M. D. A. Thomas, Chloride diffusion modeling for marine exposed concretes, Department of Civil Engineering, University of Toronto. Ontario, Canada, M5S 1A4.

6. M. D. A. Thomas and P. B. Bamforth, "Modeling Chloride Diffusion in Concrete; Effects of fly Ash and Slag," Cement and Concrete Composites, Vol.29, 1999, pp. 487 495.

7. M. R. Jones, R. K. Dhir, and J. P. Gill, "Concrete Surface Treatment: Effect of Exposure Temperature on Chloride Diffusion Resistance," Cement and Concrete Research, Vol.25, No 1, 1995, pp. 197 208.

8. Waheeb A. Al-Khaja, "Influence of Temperature, Cement Type and Level of Concrete Consolidation on Chloride Ingress in Conventional and High-Strength Concretes," Construction and Building Materials, Vol. 11, 1997, pp.9 13.

9. R. Luoa, Y. Caib, C. Wangb, and X. Huang, "Study of Chloride Binding and Diffusion in GGBS Concrete," Cement and Concrete Research, Vol.33, 2003, pp 1 7.

10. C. Andrade, J. M. Díez, and C. Alonso, "Modeling of Skin Effects on Diffusion Process in Concrete," RILEM, 1997, pp. 182 194.
11. C. Andrade, J. M. Díez and C. Alonso, Mathenatical Modeling of a Concrete Surface "Skin Effect" on Diffusion in Chloride Contaminated Media, Advanced Cement Base Material, 1997, pp.39 44.

12. J. Z. Zhang, I. M. McLoughlin, and N. R. Buenfeld, "Modeling of Chloride Diffusion into Surface-Treated Concrete," Cement and Concrete Composites, Vol.20, 1998, pp.253 261.

13. P.A.M. Basheer and E. Nolan, "Near-Surface Moisture Gradients and In Situ Permeation Tests," Construction and Building Materials, Vol.15, 2001, pp.105 114.

14. N. S. Martys, and C. F. Ferraris, "Capillary Transport in Mortars and Concrete," Cement and Concrete Research, Vol 27, No.5, 1997, pp.747 760.

15. J. K. Kim and C. S. Lee, "Moisture Diffusion of Concrete Considering Self-Desiccation at Early Ages," Cement and Concrete Research, Vol.29, 1999, pp. 1921 1927.

16. A. Buchwald, "Determination of the Ion Diffusion Coefficient in Moisture and Salt Loaded Masonry Materials by Impedance Spectroscopy," Third International PhD Symposium, Vienna, Vol.2, Oct. 2000, pp. 475 482 .

17. C. K. Larsen, Effect of Type of Aggregate, Temperature. and Drying/Rewetting on Chloride Binding and Pore Solution Composition," RILEM, 1997, pp.27 35.

18. P. Thoft-Christensen, Deterioration of Concrete Structure, First International Conference on Bridge Maintenance, Barcelona, July 2002.

19. Sampling and Testing for Chloride Ion in Concrete and Concrete Raw Materials, Designation T 260-94, American Association of State Highway and Transportation Officials.

20. The Florida Method of Test for Determining Low Level of Chlorides in Concrete and Raw Materials, designation FM 5-516, Florida Department of Transportation.

21. P.A.M. Basheer and E. Nolan, "Near-Surface Moisture Gradients and In Situ Permeation Tests," Construction and Building Materials, Vol.15, 2001, pp.105 114. 